\title{
Overexpression of CD155 relates to metastasis and invasion in osteosarcoma
}

\author{
BAOBIAO ZHUO ${ }^{1,2}$, YUAN LI $^{2}$, FENG GU $^{3}$, ZHENGWEI LI $^{2}$, QINGZENG SUN ${ }^{2}$, YINGCHUN SHI ${ }^{2}$, \\ YANG SHEN $^{2}$, FENGFEI ZHANG ${ }^{2}$, RONG WANG $^{4}$ and XIAODONG WANG ${ }^{1}$ \\ ${ }^{1}$ Department of Surgery, Children's Hospital of Soochow University, Suzhou, Jiangsu 215025; \\ ${ }^{2}$ Department of Surgery, Xuzhou Children's Hospital, Xuzhou, Jiangsu 221006; ${ }^{3}$ Department of \\ Laboratory Medicine, Xuzhou Cancer Hospital, Xuzhou, Jiangsu 221000; ${ }^{4}$ Department of Ultrasound, \\ The Affiliated Hospital of Xuzhou Medical University, Xuzhou, Jiangsu 221002, P.R. China
}

Received March 31, 2017; Accepted November 20, 2017

DOI: $10.3892 / \mathrm{ol} .2018 .8228$

\begin{abstract}
The rapid development of metastatic lesions remains the leading cause of mortality for patients with osteosarcoma. CD155 serves a key role in cancer cell migration, invasion and metastasis. However, the function and mechanism of CD155 has not been explored in osteosarcoma metastasis. In the present study, we found that CD155 was significantly upregulated in lung metastatic tissue and the highly metastatic cell line K7M2-WT (K7M2) of osteosarcoma. Overexpression of CD155 in K7M2 cells enhanced lung metastasis, while inhibition of CD155 by an anti-CD155 monoclonal antibody reduced metastasis. Blocking of CD155 also decreased migration and invasion of $\mathrm{K} 7 \mathrm{M} 2$ cells in vitro. A western blot analysis revealed that blocking of CD155 inhibits metastasis by downregulating focal adhesion kinase (FAK) and phosphorylated FAK (pFAK) in osteosarcoma. The results revealed that CD155 serves a crucial role in the metastasis of osteosarcoma by regulating FAK and may provide a novel molecular target for therapeutic intervention in metastatic osteosarcoma.
\end{abstract}

\section{Introduction}

Osteosarcomas are the most common malignant bone tumors in children and adolescent represent $5-6 \%$ of all tumors in this age group $(1,2)$. Osteosarcoma is characterized by invasion, early metastasis, and a high metastasis rate (1). Despite major advances in the multiple therapeutic strategies including tumor excision, neoadjuvant or adjuvant chemotherapy, and radiotherapy, the long-term survival rate is unsatisfactory in the metastatic setting (3-5). The metastasis of osteosarcoma is not only a sign of deterioration but also the major cause of

Correspondence to: Professor Xiaodong Wang, Department of Surgery, Children's Hospital of Soochow University, 92 Zhongnan Street, Suzhou, Jiangsu 215025, P.R. China

E-mail: wangxiaodongw2014@yeah.net

Key words: CD155, osteosarcoma, metastasis, migration, invasion treatment failure and death (6). Thus, identification of novel molecules that take part in the metastatic processes is essential for developing new therapeutic strategy for osteosarcoma.

CD155 was initially identified as a receptor based on its ability to mediate the binding of poliovirus to host cells $(7,8)$, and also known as a member of the immunoglobulin family of cell adhesion molecules $(9,10)$. CD155 is broadly distributed at low levels on epithelial and endothelial cells in many tissues (11), but overexpressed in various carcinomas including soft tissue sarcoma $(12,13)$, colorectal cancer (14), lung adenocarcinoma (15), melanoma (16), neuroblastoma and glioblastoma $(17,18)$. CD155 was subsequently shown to promote GBM cell migration and focal adhesion disassembly $(19,20)$. The downregulation of CD155 can decrease several cancer cells migration and invasion by regulating numerous invasion-associated molecules in vitro (21). These biological properties of CD155 suggest that its overexpression in many cancer cells plays a key role in their metastasis.

Therefore, the objective of this study was to establish if CD155 had a key role in the metastatic phenotypes observed in K7M2-WT (K7M2) murine high metastatic osteosarcoma cells. Our data show that CD155 activity is increased in the highly metastasis K7M2 and that this activity could be blocked by an anti-CD155 monoclonal antibody. We also show that CD155 protein level increases in vivo lung metastasis of osteosarcoma patients. Altogether, our results reveal that CD155 blocking represents a novel potential molecular target for therapeutic intervention in metastatic osteosarcoma.

\section{Materials and methods}

Human osteosarcoma specimens. A total of 8 osteosarcoma tissue specimens of 4 cases lung metastasis and 4 cases no metastasis were obtained from the hospital's Department of Pathology database. Without any preoperative treatment, all 8 cases were pathologically diagnosed as osteosarcoma postoperatively. This study was approved by the Ethics Committee of the Xuzhou Children's Hospital (Xuzhou, China), and all specimens were collected from patients who provided written informed consent in accordance with the principles of the Declaration of Helsinki and Good Clinical Practice Guidelines. 
Cell line and antibodies. The murine highly metastatic osteosarcoma cell line K7M2 cells was purchased from the American Type Culture Collection (ATCC; Manassas, VA, USA) and grown in Dulbecco's modified Eagle's medium (DMEM; Gibco-BRL, Grand Island, NY, USA) containing $10 \%$ fetal bovine serum (FBS) and supplemented with $100 \mathrm{U} / \mathrm{ml}$ penicillin-streptomycin (Gibco-BRL) in a humidified $37^{\circ} \mathrm{C}$ incubator with $5 \% \mathrm{CO}_{2}$. Purified rat anti-mouse $\mathrm{CD} 155$ (isotype control, purified Rat IgG2a), PE anti-mouse CD155, and anti-human CD155 were purchased from BioLegend, Inc. (San Diego, CA, USA); rabbit anti-focal adhesion kinase (FAK) and anti-phospho-FAK (Tyr397) were purchased from Cell Signaling Technology, Inc. (Danvers, MA, USA).

Reverse transcription-semi quantitative polymerase chain reaction ( $R T$-sqPCR). The mRNA expression of CD155 was tested by RT-PCR. All of the reagents were purchased from Qiagen and all methods were according to the manufacturer's instructions. The total RNA was extracted from cells using QIAshredders (cat. no. 79654). PCR was performed with CD155 primers: sense, 5'-GCCCTCGAATGTGAATGGAA-3' and antisense, 5'-TGATGTTCTTGCCGTCT-3'; GAPDH primers: sense, 5'-TTAGCACCCCTGGCCAAGG-3' and antisense, 5'-CTTACTCCTTGGAGGCCATG-3'. The products of PCR were analyzed by $1.0 \%$ agarose gel.

Western blot analysis. Cells were harvested and lysed, and the cleared lysates (30-50 $\mu \mathrm{g} /$ well) were separated on $10 \%$ Tris/glycine polyacrylamide gel electrophoresis (PAGE) gels under standard conditions. Then proteins were then transferred to a nitrocellulose membrane and incubated overnight at $4^{\circ} \mathrm{C}$ with the primary antibodies. Membranes were then washed and incubated with alkaline phosphatase conjugated the appropriate second antibody for $2 \mathrm{~h}$, and developed using the NBT/BCIP (nitro-blue tetrazolium chloride/5-bromo-4-chloro-3'-indolyphosphate p-toluidine salt) color substrate (Promega, Madison, WI, USA). The bands on the membranes were visualized with an Odyssey ${ }^{\circledR}$ CLx Infrared Imaging System (LI-COR Biotechnology, Lincoln, NE, USA).

Flow cytometric analysis. Flow cytometry was performed on a FACSCanto (Becton-Dickinson, San Jose, CA, USA). Briefly, $1 \times 10^{6}$ cells were harvested, washed, and resuspended in $100 \mu \mathrm{lPBS}$, and then $5 \mu \mathrm{l}$ PE-conjugated anti-mouse CD155 antibodies, or with control rat IgG were added to sample. After incubation at $4^{\circ} \mathrm{C}$ for $30 \mathrm{~min}$, the cells were washed with PBS, resuspended in $300 \mu \mathrm{l}$ buffer, and analyzed by the flow cytometer.

Tumor growth and metastasis in nude mice. Male BALB/c nude mice (4-5 weeks old) were obtained from the Shanghai Experimental Animal Center of the Chinese Academy of Sciences (Shanghai, China) and quarantined for a week before the tumor implantation. All of the experimental procedures were approved by the Institutional Animal Care and Use Committee of Xuzhou Medicine College under protocol SYXK-2010-0011. For lung metastasis experiments, K7M2 cells $\left(5 \times 10^{6}\right.$ cells in $1 \mathrm{ml}$ of PBS) were pre-incubated with anti-CD155 $\mathrm{mAb}$ or control rat $\mathrm{IgG}(1 \mathrm{mg} / \mathrm{ml})$ at $4^{\circ} \mathrm{C}$ for $30 \mathrm{~min}$

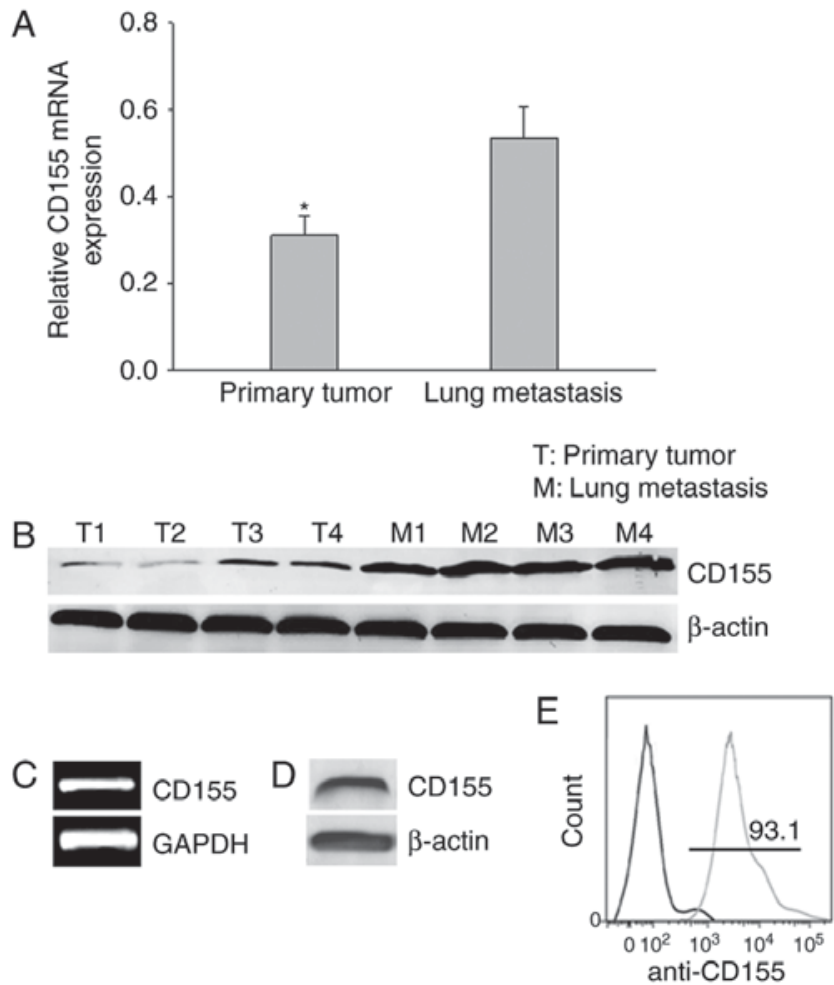

Figure 1. Upregulation of CD155 is detected in the lung metastatic tissues and highly metastatic cell line of osteosarcoma. (A) The expression of CD155 was determined in 4 pairs of primary tumor tissues and the corresponding metastatic tissues by reverse transcription-semi quantitative polymerase chain reaction. GAPDH was used as the internal control. Data are presented as the mean \pm standard deviation $(\mathrm{n}=8),{ }^{*} \mathrm{P}<0.05$. (B) The CD155 protein level was detected by western blot analysis in 4 paired tissues. (C) CD155 mRNA expression was evaluated in K7M2 cells using RT-PCR. (D) The CD155 protein expression was detected in $\mathrm{K} 7 \mathrm{M} 2$ cells by western blot analysis (E) Cell surface expression levels of CD155 on K7M2 cells were detected using flow cytometric analysis.

and washed twice with PBS. The resulting cells $\left(1 \times 10^{6}\right.$ cells in $200 \mu \mathrm{l}$ of PBS) were injected into the tail vein of mice. To evaluate the metastasis of $\mathrm{K} 7 \mathrm{M} 2$ cells, nude mice received K7M2 cells treated with the anti-CD155 mAb, or with rat IgG or PBS as controls. After 21 days, the mice were sacrificed and the tumor nodules on the surface of the lungs were counted under a dissecting microscope.

For xenograft tumor experiments, K7M2 cells $\left(1 \times 10^{6}\right)$ were subcutaneously injected into the right flank of the BALB/c nude mice. When the tumors reached $100-150 \mathrm{~mm}^{3}$, the mice were randomly divided into three groups (eight mice per group) and treated with intravenous injections of $500 \mu \mathrm{g}$ of anti-CD155 $\mathrm{mAb}$ or control rat IgG three times per week for 6 weeks. The tumors were monitore every week by measuring the tumor size using a caliper for 6 weeks. The tumor volume was calculated by the following formula: Volume $\left(\mathrm{mm}^{3}\right)=$ length $\mathrm{x}$ width ${ }^{2} / 2$. The differences in the tumor growth were tested for statistical significance. After 6 weeks, the mice were sacrificed and the final tumor weights were measured.

Cell migration and invasion assay. K7M2 cells were pre-incubated with anti-CD155 $\mathrm{mAb}$ or rat $\mathrm{IgG}$ at $4^{\circ} \mathrm{C}$ for $30 \mathrm{~min}$ and washed twice with PBS. The treated K7M2 cells were resuspended in serum-free DMEM medium. 
A
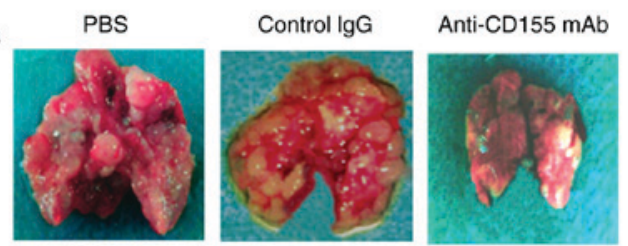

C

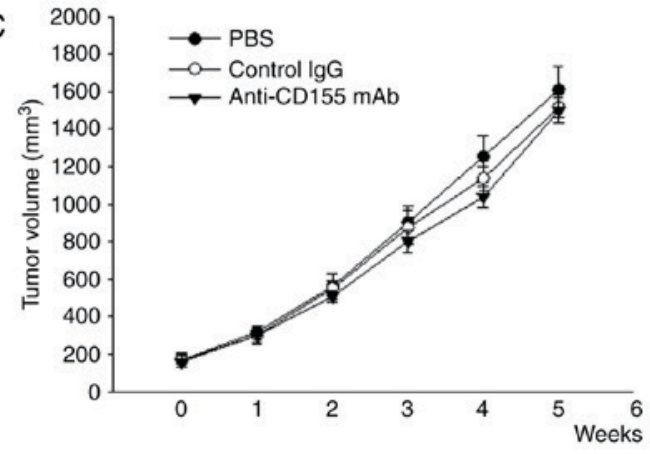

B

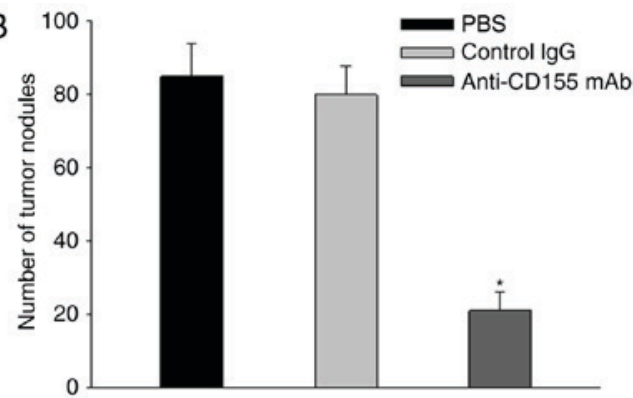

D

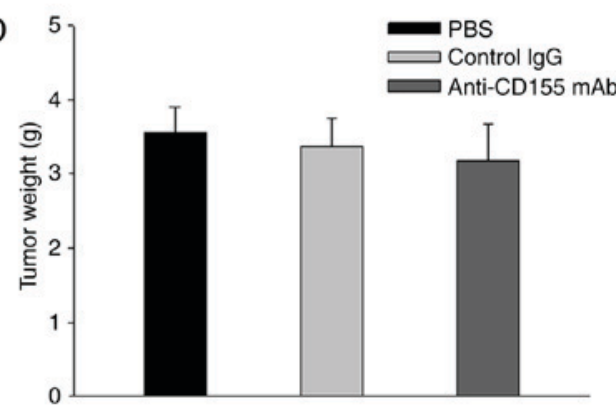

Figure 2. CD155 expression controls lung metastasis in mice. Inhibition of cancer metastasis by an anti-CD155 mAb. K7M2 cells were pretreated with PBS, control rat $\mathrm{IgG}$ or anti-CD155 mAb. BALB/c mice were given the treated K7M2 cells $\left(1 \times 10^{6}\right)$ by i.v. injection and the numbers of pulmonary metastases in the different groups were counted on day 21 after the injection. (A) Images of metastasized lungs. (B) Numbers of tumor nodules in the lungs. Lack of effect of the anti-CD155 mAb on tumor growth. The mice with tumors reached $100-150 \mathrm{~mm}^{3}$ were injected i.v. with PBS, control rat IgG or anti-CD155 mAb three times per week for 4 weeks. The tumor dimensions were measured and the mean tumor volume in each group was monitored. (C) Tumor growth curve. (D) Tumor weight on day 42 . Data are presented as the mean \pm standard deviation $(n=8),{ }^{*} \mathrm{P}<0.05$.

The cell migration or invasion assay was performed in a 24-well Transwell unit (cat. no. CLS3398; Sigma-Aldrich; Merck KGaA, St. Louis, MO, USA), or 24-well Transwell unit coated with Matrigel (cat. no. 354578; Becton-Dickinson), respectively. The lower chambers of the Transwell units were filled with serum-free medium, and the upper chambers were seeded with $1 \times 10^{5}$ cells from each treatment group in triplicate wells. After 24 and $48 \mathrm{~h}$ incubations, the cells that had passed through the filter into the lower wells were counted. The experiments were performed four times, and the results were recorded as the mean of these experiments.

Statistical analysis. The values were expressed as the mean \pm standard deviation (SD). The statistical analysis of the results was performed using a one-way analysis of variance with Student-Newman-Keuls post hoc tests or Student's t-test. P-values $<0.05$ were considered to indicate a statistically significant difference.

\section{Results}

CD155 is upregulation in the lung metastatic tissues and highly metastatic cell line of osteosarcoma. Firstly, we analysed the expression of CD155 mRNA in 4 pairs of osteosarcoma tissues and the corresponding lung metastatic tissues using quantitative real-time PCR. The relative expression level of CD155 was significantly upregulated in the metastatic lung tissues compared with their primary counterparts $(\mathrm{P}<0.01)$ (Fig. 1A). Western blot analysis showed that the expression of CD155 protein was increased in lung metastatic tissues of osteosarcoma (Fig. 1B). Next, we detected the expression of CD155 mRNA and protein in highly metastatic murine osteosarcoma cell line K7M2 cells. As shown in Fig. 1C and D, both the mRNA and the protein of CD155 were expressed in the highly metastatic K7M2 cells. In addition, we used fluorescent-activated cell sorting (FACS) analysis to examine the expression levels of cell surface CD155 in K7M2 cells. CD155 was strongly expressed in cell surface of osteosarcoma cell line K7M2 (Fig. 1E). These results suggest that CD155 may play an important role in the osteosarcoma progression and metastasis.

CD155 blockade by anti-CD155 mAb decreases K7M2 cells experimental lung metastasis in vivo. To evaluate the metastatic potential of CD155 on highly metastatic K7M2 cells, we cultured the cells with antibodies against CD155 and compared the rates of metastasis to the lungs among K7M2 cells treated with anti-CD155 mAb, or with rat IgG or PBS. We injected each treated-cell into the tail vein of BALB/c nude mice. The mice were killed on day 21 and counted the numbers of tumor nodules in the lungs. The lung size was smaller in mice injected with K7M2 cells treated with the anti-CD155 mAb than in control mice treated with IgG or PBS (Fig. 2A). The number of tumor nodules formed by K7M2 cells treated with the anti-CD155 mAb was $(21 \pm 5)$ and reduced to a quarter of the number formed by control K7M2 cells treated with IgG or PBS $(\mathrm{P}<0.01)$ (Fig. 2B). These results suggest that CD155 may play an important role in the osteosarcoma lung metastasis.

Furthermore, we established xenografts tumor model to evaluate the effect of the anti-CD155 mAb on tumor growth in the mice subcutaneous tissue. When the tumors reached 
A
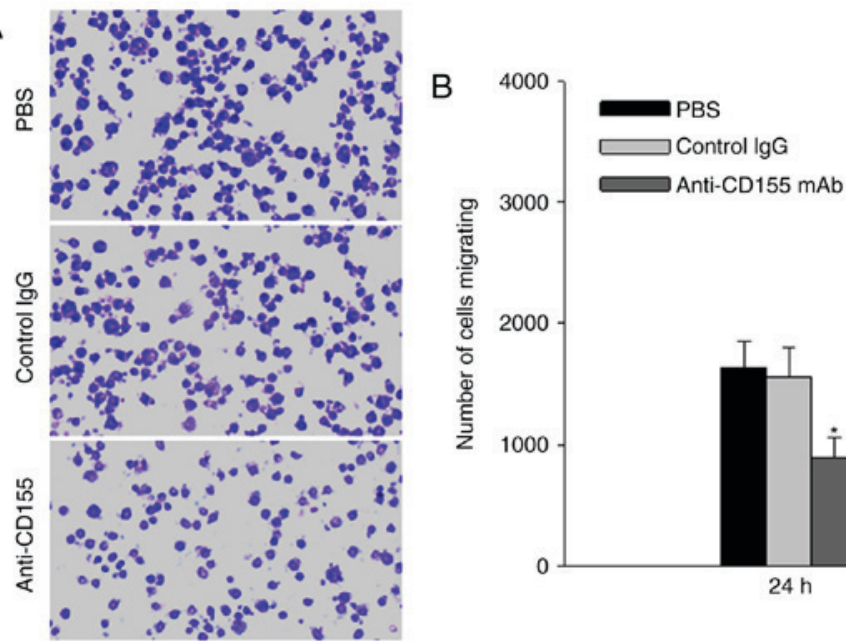

C

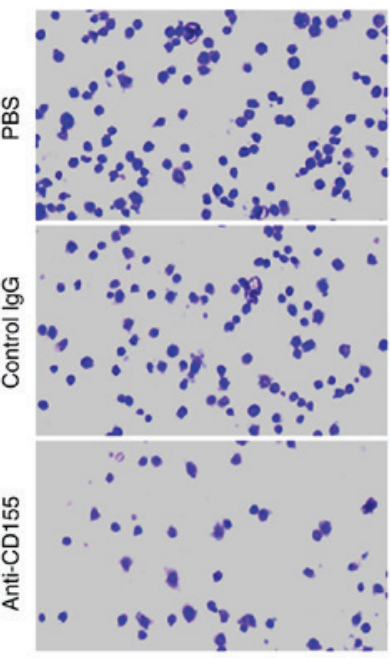

D

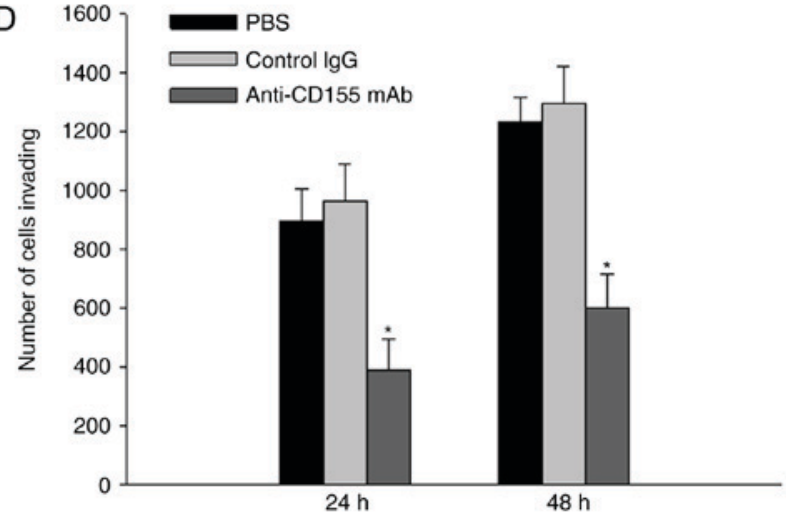

Figure 3. CD155 expression controls osteosarcoma cells migration and invasion. K7M2 cells were treated with PBS, control rat immunoglobulin G or anti-CD155 mAb to investigate cell migration and invasion at 24 and $48 \mathrm{~h}$ subsequent to treatment. (A) The crystal violet staining of the K7M2 cells that passed through the polycarbonate membrane of the Transwell migration chamber at $48 \mathrm{~h}$. (B) The number of cells that passed through the Transwell migration chamber. (C) The crystal violet staining of the K7M2 cells that passed through the polycarbonate membrane of the Transwell invision chamber at $48 \mathrm{~h}$. (D) The number of cells that passed through the Transwell invision chamber. Data are presented as the mean \pm standard deviation from four independent experiments $(\mathrm{n}=4),{ }^{*} \mathrm{P}<0.05$.

$100-150 \mathrm{~mm}^{3}$, the mice were treated with intravenous injections of anti-CD155 $\mathrm{mAb}$ or control rat IgG three times per week for 6 weeks. As shown in Fig. 2C, tumor growth was measured per week, and the mean volumes in cubic millimeters were calculated. The mice were killed on day 42 and the tumor weights were measured (Fig. 2D). Tumors appeared in all three mouse groups, and injection of the anti-CD155 mAb had no effect on the tumor size and weight $(\mathrm{P}>0.05)$. These results indicate that the anti-CD155 mAb does not affect the proliferation of cancer cells in vivo.

CD155 blockade by anti-CD155 $m A$ b reduces $K 7 M 2$ cells migration and invasion in vitro. The Transwell system was used to assay the migration and invasion of K7M2 cells treated with anti-CD155 mAb, or with IgG or PBS as control. The number of cells that migrated to the Transwell membrane in the anti-CD155 mAb treatment group was significantly lower than in the IgG or PBS group ( $\mathrm{P}<0.01)$ (Fig. 3A and B). The number of osteosarcoma K7M2 cells that invaded the membrane was significantly lower when comparing the anti-CD155 mAb treatment group to the $\mathrm{IgG}$ or PBS groups $(\mathrm{P}<0.01)$ (Fig. 3C and $\mathrm{D})$. These results suggest that $\mathrm{CD} 155$ high expression play a key role in the migration and invasion of osteosarcoma cells.

CD155 inhibits osteosarcoma metastasis through repressing FAK and pFAK expression. FAK overexpression has been found in human osteosarcoma, and affects the migration and invasion ability of osteosarcoma cells (22). To determine whether CD155 is related to FAK protein levels in osteosarcoma, we performed western blot analysis for FAK and pFAK. K7M2 cells were pre-incubated with anti-CD155 mAb or rat $\mathrm{IgG}$ at $4^{\circ} \mathrm{C}$ for $30 \mathrm{~min}$, washed twice with PBS, resuspended in DMEM medium, and cultured for $24 \mathrm{~h}$ in a humidified $37^{\circ} \mathrm{C}$ incubator with $5 \% \mathrm{CO}_{2}$. The treated cells were subjected to western blot analysis. As shown in Fig. 4A, CD155 blockade decreased FAK and pFAK protein levels in K7M2 cells $(\mathrm{P}<0.05)$. The results suggested that the overexpression of CD155 in osteosarcoma cells might be related to FAK in cell migration. Furthermore, lung metastatic tissues expressed higher levels of FAK and pFAK than primary tumor tissues of 


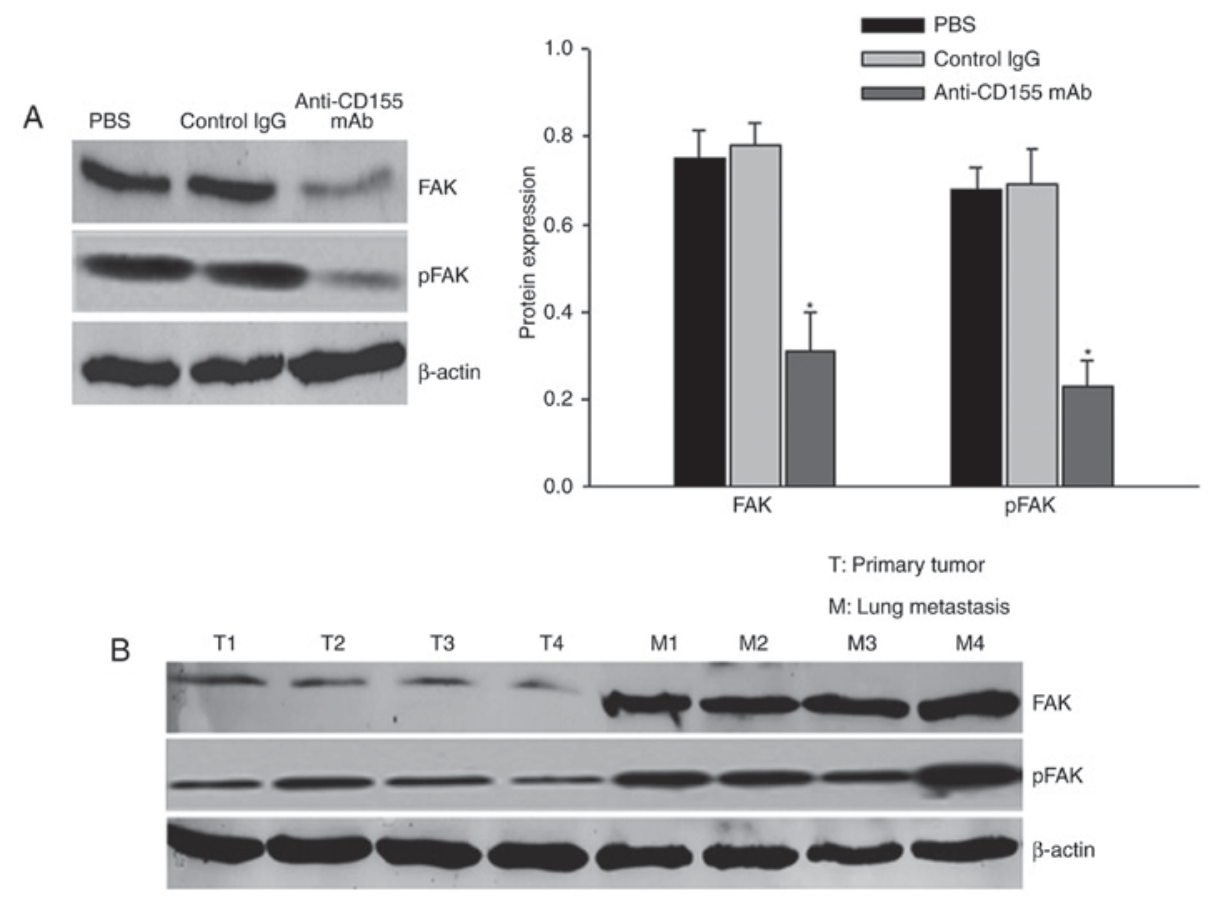

Figure 4. Western blot analysis for FAK and pFAK expression in osteosarcoma cells after treatment with anti-CD155 mAb or in osteosarcoma tissue. (A) Immunoblotting showed that CD155 blockade decreased FAK and pFAK protein levels $\sim 60-70 \%$ relative to cells treated with control immunoglobulin G in K7M2 cells. Data are presented as the mean \pm standard deviation from four independent experiments $(\mathrm{n}=4)$, ${ }^{*} \mathrm{P}<0.05$. (B) Lung metastatic tumor tissues expressed higher levels of FAK and pFAK than primary tumor tissues. FAK, focal adhesion kinase; p, phosphorylated.

human osteosarcoma (Fig. 4B). These data strongly support a role of CD155 in metastasis and correlates with FAK.

\section{Discussion}

Osteosarcoma is the most common bone cancer in children and young adults. It is the major cause of cancer-associated mortality in these age groups due to fatal lung metastasis. Unfortunately, $20 \%$ of patients present with pulmonary metastatic disease at initial diagnosis, and 30-40\% patients with the primary diagnosis of non-metastatic osteosarcoma eventually develop pulmonary metastasis $(23,24)$. Survival for these patients is very poor despite intensive therapy with surgery, chemotherapy, and/or radiotherapy $(25,26)$. Thus, it is urgent to study the metastatic mechanisms for effective assessment of the predict survival and treatment of osteosarcoma.

CD155 is overexpression in many types of human and rodent cancer cells $(14-16,27,28)$. Atsumi et al report that CD155 is widely expressed in all 12 bone and soft tissue sarcoma cell lines and soft tissue sarcoma tissue samples, which is associated with the clinical outcome of the patients with soft tissue sarcoma $(12,13)$. These data reinforce the need for a better understanding of the mechanisms of action of CD155 to refine the development of new anticancer targets. In the present study, we demonstrated that CD155 enhances osteosarcoma cells metastasis to the lungs.

An activity for CD155 in osteosarcoma metastasis is powerfully supported by our experiments of lung metastasis using manipulated osteosarcoma cells in mice. Indeed, our in vivo experiments showed that overexpression of CD155 increased osteosarcoma cells metastatic behavior dramatically by acting on pulmonary metastatic foci number and size.
More important, we demonstrated that CD155 blocking by anti-CD155 mAb markedly reduced osteosarcoma lung metastasis occurrence in mice. Furthermore, we found that injection of the anti-CD155 mAb had no effect on the xenografts tumor growth in mice. The data indicate that the anti-CD155 mAb does not affect the proliferation of cancer cells in vivo. These results indicate that attenuation of $\mathrm{CD} 155$ reduces tumor metastatic progression in vivo.

Tumor metastasis is a complex process that is required for many aspects of normal and disease biology (29-31). The migration of malignant cells largely determines their ability for tumor metastasis (32-34). Our in vitro experiments showed that $\mathrm{CD} 155$ overexpression led to an increase in cell migration and invasion, whereas CD155 blocking reduced both migration and invasion of osteosarcoma cells. FAK is known to be crucial for adhesion turnover at the cell front, a process central to migration $(35,36)$. Normal tissues have low expression of FAK, while cancer cells significantly overexpress this protein $(37,38)$. Oda et al studies showed the activation of CD155a could reduce the phosphorylation of FAK (39). CD155 knockdown via shRNA inhibited colon cancer and lung adenocarcinoma cell migration and invasion by reduction expression of FAK $(40,41)$. In the present study, both FAK and CD155 are strongly expressed in osteosarcoma cells with high migration and invasion abilities. Moreover, osteosarcoma cells added with anti-CD155 mAb have an about $60-70 \%$ reduction in the expression of FAK proteins. These results supported that the overexpression of CD155 in cancer cells might be related to FAK in cancer cell migration.

The results of this study also showed that the expression of CD155 and FAK in osteosarcoma tissues from patients with positive lung metastases was significantly higher than 
that in tissues from negative lung metastases $(\mathrm{P}<0.05)$. The data indicate that CD155 and FAK expression correlates with tumor invasiveness in human osteosarcoma. Future studies of the analysis of the evolution of primary and metastatic tumors are needed to conclude on the predictive value of CD155 and FAK expression level on tumor development in human osteosarcoma.

In summary, our data demonstrate that CD155 expression controls cell invasion and migration in vitro and tumor metastasis in vivo. CD155 blocking decreased the expression of FAK, which affected the migration ability of the cells. The study provides a break-through in the study of human osteosarcoma metastasis and finds a molecular basis for a novel therapeutic strategy to reduce osteosarcoma metastasis.

\section{Acknowledgements}

This study was supported by the National Natural Science Foundation of China (no. 81502566) and Jiangsu Provincial Medical Youth Talent of Invigorating Health Care through Science, Technology, and Education (no. ONRC2016373).

\section{References}

1. Ritter J and Bielack SS: Osteosarcoma. Ann Oncol 21 (Suppl 7): vii320-vii325, 2010.

2. Eftekhari F: Imaging assessment of osteosarcoma in childhood and adolescence: Diagnosis, staging, and evaluating response to chemotherapy. Cancer Treat Res 152: 33-62, 2009.

3. Luetke A, Meyers PA, Lewis I and Juergens H: Osteosarcoma treatment-where do we stand? A state of the art review. Cancer Treat Rev 40: 523-532, 2014.

4. Anninga JK, Gelderblom H, Fiocco M, Kroe JR, Taminiau AH Hogendoorn PC and Egeler RM: Chemotherapeutic adjuvant treatment for osteosarcoma: Where do we stand? Eur J Cancer 47 2431-2445, 2011.

5. Anderson ME: Update on survival in osteosarcoma. Orthop Clin North Am 47: 283-292, 2016.

6. van Schie R, Hagleitner M, Hoogerbrugge P, Flucke U, Schreuder H and Te Loo M: Overall survival trends in pediatric osteosarcoma patients over the past three decades. J Clin Oncol 27: 10041, 2009.

7. Nobis P, Zibirre R, Meyer G, Kühne J, Warnecke G and Koch G: Production of a monoclonal antibody against an epitope on HeLa cells that is the functional poliovirus binding site. J Gen Virol 66 2563-2569, 1985.

8. Mendelsohn CL, Wimmer E and Racaniello VR: Cellular receptor for poliovirus: Molecular cloning, nucleotide sequence, and expression of a new member of the immunoglobulin superfamily. Cell 56: 855-865, 1989.

9. Takai Y, Irie K, Shimizu K, Sakisaka T and Ikeda W: Nectins and nectin-like molecules: Roles in cell adhesion, migration, and polarization. Cancer Sci 94: 655-667, 2003.

10. Ogita H, Ikeda W and Takai Y: Roles of cell adhesion molecules nectin and nectin-like molecule-5 in the regulation of cell movement and proliferation. J Microsc 231: 455-465, 2008.

11. Bottino C, Castriconi R, Pende D, Rivera P, Nanni M, Carnemolla B, Cantoni C, Grassi J, Marcenaro S, Reymond N, et al: Identification of PVR (CD155) and Nectin-2 (CD112) as cell surface ligands for the human DNAM-1 (CD226) activating molecule. J Exp Med 198: 557-567, 2003.

12. Atsumi S, Matsumine A, Toyoda H, Niimi R, Iino T and Sudo A Prognostic significance of CD155 mRNA expression in soft tissue sarcomas. Oncol Lett 5: 1771-1776, 2013.

13. Atsumi S, Matsumine A, Toyoda H, Niimi R, Iino T, Nakamura T, Matsubara T, Asanuma K, Komada Y, Uchida A and Sudo A: Oncolytic virotherapy for human bone and soft tissue sarcomas using live attenuated poliovirus. Int J Oncol 41: 893-902, 2012.

14. Masson D, Jarry A, Baury B, Blanchardie P, Laboisse C, Lustenberger $\mathrm{P}$ and Denis MG: Overexpression of the CD155 gene in human colorectal carcinoma. Gut 49: 236-240, 2001 .
15. Nakai R, Maniwa Y, Tanaka Y, Nishio W, Yoshimura M, Okita Y, Ohbayashi C, Satoh N, Ogita H, Takai Y and Hayashi Y: Overexpression of Necl-5 correlates with unfavorable prognosis in patients with lung adenocarcinoma. Cancer Sci 101: 1326-1330, 2010.

16. Chan CJ, Andrews DM, McLaughlin NM, Yagita H, Gilfillan S, Colonna $\mathrm{M}$ and Smyth MJ: DNAM-1/CD155 interactions promote cytokine and NK cell-mediated suppression of poorly immunogenic melanoma metastases. J Immunol 184: 902-911, 2010.

17. Ochiai H, Moore SA, Archer GE, Okamura T, Chewning TA, Marks JR, Sampson JH and Gromeier M: Treatment of intracerebral neoplasia and neoplastic meningitis with regional delivery of oncolytic recombinant poliovirus. Clin Cancer Res 10: 4831-4838, 2004.

18. Castriconi R, Dondero A, Corrias MV, Lanino E, Pende D, Moretta L, Bottino C and Moretta A: Natural killer cell-mediated killing of freshly isolated neuroblastoma cells: Critical role of DNAX accessory molecule-1-poliovirus receptor interaction. Cancer Res 64: 9180-9184, 2004.

19. Sloan KE, Eustace BK, Stewart JK, Zehetmeier C, Torella C, Simeone M, Roy JE, Unger C, Louis DN, Ilag LL and Jay DG: CD155/PVR plays a key role in cell motility during tumor cell invasion and migration. BMC Cancer 4: 73, 2004.

20. Sloan KE, Stewart JK, Treloar AF, Matthews RT and Jay DG: CD155/PVR enhances glioma cell dispersal by regulating adhesion signaling and focal adhesion dynamics. Cancer Res 65: 10930-10937, 2005.

21. Enloe BM and Jay DG: Inhibition of Necl-5 (CD155/PVR) reduces glioblastoma dispersal and decreases MMP-2 expression and activity. J Neurooncol 102: 225-235, 2011.

22. Feng S, Shi X, Ren KE, Wu S and Sun X: Focal adhesion kinase is involved in the migration of human osteosarcoma cells. Oncol Lett 9: 2670-2674, 2015.

23. Kager L, Zoubek A, Pötschger U, Kastner U, Flege S, Kempf-Bielack B, Branscheid D, Kotz R, Salzer-Kuntschik M, Winkelmann W, et al: Primary metastatic osteosarcoma: Presentation and outcome of patients treated on neoadjuvant cooperative osteosarcoma study group protocols. J Clin Oncol 21: 2011-2018, 2003.

24. Bielack SS, Kempf-Bielack B, Branscheid D, Carrle D, Friedel G, Helmke K, Kevric M, Jundt G, Kühne T, Maas R, et al: Second and subsequent recurrences of osteosarcoma: Presentation, treatment, and outcomes of 249 consecutive cooperative osteosarcoma study group patients. J Clin Oncol 27: 557-565, 2009.

25. Collins M, Wilhelm M, Conyers R, Herschtal A, Whelan J, Bielack S, Kager L, Kühne T, Sydes M, Gelderblom H, et al: Benefits and adverse events in younger versus older patients receiving neoadjuvant chemotherapy for osteosarcoma: Findings from a meta-analysis. J Clin Oncol 31: 2303-2312, 2013.

26. Petrilli AS, de Camargo B, Odone Filho V, Lustosa D, Borsato ML, Calheiros LM, Brunetto AL, Barreto JH and Ferraro AA: Fifteen years experience of the Brazilian osteosarcoma treatment group (BOTG). J Clin Oncol 27 (15 Suppl): S10039, 2009.

27. Nishiwada S, Sho M, Yasuda S, Shimada K, Yamato I, Akahori T, Kinoshita S, Nagai M, Konishi N and Nakajima Y: Clinical significance of CD155 expression in human pancreatic cancer. Anticancer Res 35: 2287-2297, 2015.

28. Qu P, Huang X, Zhou X, Lü Z, Liu F, Shi Z, Lü L, Wu Y and Chen Y: Loss of CD155 expression predicts poor prognosis in hepatocellular carcinoma. Histopathology 66: 706-714, 2015.

29. Valastyan S and Weinberg RA: Tumor metastasis: Molecular insights and evolving paradigms. Cell 147: 275-292, 2011.

30. Steeg PS: Tumor metastasis: Mechanistic insights and clinical challenges. Nat Med 12: 895-904, 2006.

31. Wan L, Pantel K and Kang Y: Tumor metastasis: Moving new biological insights into the clinic. Nat Med 19: 1450-1464, 2013.

32. Bravo-Cordero JJ, Hodgson L and Condeelis J: Directed cell invasion and migration during metastasis. Curr Opin Cell Biol 24: 277-283, 2012.

33. Entschladen F, Drell TL IV, Lang K, Joseph J and Zaenker KS: Tumour-cell migration, invasion, and metastasis: Navigation by neurotransmitters. Lancet Oncol 5: 254-258, 2004.

34. Le Dévédec SE, Yan K, de Bont H, Ghotra V, Truong H, Danen EH, Verbeek F and van de Water B: Systems microscopy approaches to understand cancer cell migration and metastasis. Cell Mol Life Sci 67: 3219-3240, 2010.

35. Baumann K: Cell adhesion: FAK or talin: Who goes first? Nat Rev Mol Cell Biol 13: 138, 2012. 
36. Lee S, Qiao J, Paul P, O'Connor KL, Evers MB and Chung DH: FAK is a critical regulator of neuroblastoma liver metastasis. Oncotarget 3: 1576-1587, 2012.

37. Golubovskaya VM, Conway-Dorsey K, Edmiston SN, Tse CK, Lark AA, Livasy CA, Moore D, Millikan RC and Cance WG: FAK overexpression and p53 mutations are highly correlated in human breast cancer. Int J Cancer 125: 1735-1738, 2009.

38. Golubovskaya VM, Finch R, Kweh F, Massoll NA, Campbell-Thompson M, Wallace MR and Cance WG: p53 regulates FAK expression in human tumor cells. Mol Carcinog 47: 373-382, 2008
39. Oda T, Ohka S and Nomoto A: Ligand stimulation of CD155alpha inhibits cell adhesion and enhances cell migration in fibroblasts. Biochem Biophys Res Commun 319: 1253-1264, 2004.

40. Zheng Q, Wang B, Gao J, Xin N, Wang W, Song X, Shao Y and Zhao C: CD155 knockdown promotes apoptosis via AKT/Bcl-2/Bax in colon cancer cells. J Cell Mol Med: Aug 16, 2017 (Epub ahead of print).

41. Tane S, Maniwa Y, Hokka D, Tauchi S, Nishio W, Okita Y and Yoshimura M: The role of Necl-5 in the invasive activity of lung adenocarcinoma. Exp Mol Pathol 94: 330-335, 2013. 